\title{
CENAS DE ASSALTO SEXUAL. UM ESTUDO DE CASO EM HOKUSAI
}

RESUMO: Através da tradução e análise de duas cenas de assalto sexual representadas por Hokusai, visa-se caracterizar um aspecto da sexualidade compreendida entre os citadinos do período Edo, particularmente relacionando texto e imagem. Mostra-se uma particularidade do gênero ninjôbon no universo das estampas eróticas shunga de Hokusai e sua relação com a compaixão (aware).

PALAVRAS-CHAVE: ukiyo-e shunga, Katsushika Hokusai, Manpuku Wagôjin, tradução e análise de assaltos sexuais.

ABSTRACT: Through the translation and analysis of two sexual assaults represented by Hokusai, it is aimed to characterize one sexual aspect among Edo period townsmen, particularly relating text and image. It is shown specificities of the ninjôbon literary genre in Hokusai's erotic prints universe and its relation with pathos (aware).

KEYWORDS: ukiyo-e shunga, Katsushika Hokusai, Manpuku Wagôjin, translation and analysis of sexual assaults.

As relações amorosas representadas nas estampas eróticas shunga são do mais variado espectro, englobando situações reais e imaginárias, realistas e simbólicas, lógicas e irracionais, podendo chegar a se compor em alegorias arduamente decifradas. Se não faltam as etéreas imagens primaveris de sexo enquanto alegria e alegoria da vida, também são numerosas as que tratam da gente "feia, suja e malvada" e, é claro, normalmente despossuída.

A relação entre sexo e poder está mais que estudada, sendo a obra mais célebre a "História da Sexualidade" de Michel Foucault, e mais que apontada no ocidente se encontra 
a centralidade do homem enquanto consumidor e perpetrador na produção pornográfica moderna, especialmente por feministas ferozes. Independentemente dessas concepções, a representação erótica no Japão, como apontam Hayakawa, Mihashi e Shirakura, livre dos freios de uma moral religiosa cristã, trata o sexo como fonte de alegria e riso em geral, diferenciando-se neste sentido da pornographie.

Se, por um lado, "alegria" e "riso" não se encontram presentes em toda a produção de shunga, por outro lado, seu caráter de "expressão de verdade" (como aponta Hayakawa) não pode certamente ser negado, pois pululam as representações dos excluídos da fruição do sexo, seja pela baixa extração social e/ou econômica, seja por incapacidade fisica ou psicológica.

O presente texto visa, justamente, enfocar uma situação na qual "alegria" e "riso" parecem não ser parelhas presentes: duas situações de assalto sexual na obra de Katsushika Hokusai, Manpuku Wagôjin 万福和合神 (Deuses da Harmonia e da Extrema Felicidade), de 1833 , em que duas protagonistas têm suas histórias de vida relatas de modo alternado. A pobre Otsubi e a filha de uma casa pródiga Osane percorrem um caminho em meio a algumas atividades comuns às mulheres (filha, esposa, babá, concubina, mulher profissional do sexo em diferentes níveis e extrações econômicas, mãe, herdeira de casa comercial, viúva predadora sexualmente) e sofrem a gangorra dos destinos.

Manpuku Wakôjin 万福和合神 (Deuses da Harmonia e da Felicidade Extrema') é obra prima característica do talento de Hokusai. Embora a produção xilográfica seja posterior, no fim do terceiro volume encontra-se a data referente ao ano 4 da era Bunsei (1821), quando o pintor contaria com 61 anos de idade, fase em que toma a si o empreendimento de, ele mesmo, fazer as pinturas e escrever o texto de gênero yomihon 本 e também de livros eróticos. O pesquisador Fukuda Kazuhiko aponta sua especialidade em criar imagens propícias aos livros cômicos (kokkeibon 滑稽本) e seu interesse também se associar às narrativas românticas (ninjôbon 人情本) de Tamenaga Shunsui 為永春水. Como apontado em estudo anterior ${ }^{2}$, se ukiyoe e ukiyo-zôshi se originam em paralelo, a pintura continuou sendo assim apodada, enquanto a literatura recebeu outras denominações. Continuaram, entretanto, intimamente conectadas.

Embora de pequenas dimensões, a riqueza de detalhes de impressão, a generosidade no uso da cor e, obviamente, a composição e os desenhos de Hokusai resultam por igualar a obra às mais ambiciosas produzidas em papéis maiores e ricos pigmentos, inclusive superando muitas.

O título alude à divindade muito popular nos fins do período Edo, Fukurokuju 福 禄寿, um dos sete deuses da fortuna que prometem a felicidade, a riqueza e a longevidade. Fukurokuju também foi cultuado como deus da harmonia entre os casais, uma crença de

1. Outras traduções encontradas, somente do titulo: "The gods of myriad conjugal delights", "The gods of Intercourse".

2. In Madalena Hashimoto: Escritura e Pintura do Mundo Flutuante: Ihara Saikaku e ukiyo-zôshi; Hishikawa Moronobu e ukiyo-e. 
fundo taoista importada da região sul da China e que ainda hoje persiste sendo popular na China, Honkong, Taiwan e Okinawa.

Os três volumes trazem capítulos eróticos que se interligam: uma moça chamada Osane, proveniente de um lar de prosperidade econômica, e outra de nome Otsubi, nascida em lar muito pobre, servem de paralelo para um enredo típico de romances românticos do tipo ninjôbon, que, quando em peregrinação erótica por muitos rincões discrimina claramente seus lados luminosos e obscuros, de acordo com um destino já pré-traçado de ligações cármicas. Conquanto impregnado de compadecimento pelos "sentimentos humanos" de suas protagonistas, o estilo direto, sarcástico e hilariante revela bem a pena de Hokusai enquanto escritor.

Não sendo escopo desta análise a estrutura da obra enquanto obra literária ou narrativa, e sim, uma reflexão sobre os assaltos sexuais que as protagonistas enfrentaram, abreviar-se-ão cenas e atenuantes. A primeira cena que nos serve de fonte provém do Livro 1, imagem 7, intitulada "A História de Otsubi". Aos 12 anos de idade, Otsubi vai trabalhar para ajudar seus pais, como babá e encarregada de serviços domésticos. Dois rapazes, com o pretexto de comprar queijo e pasta de soja, estupram-na. Ela fica num estado lastimável, as partes todas arrebentadas, e assim perde a virgindade, sem nenhum prazer. Como portam apenas uma espada e estão vestidos bem sumariamente, pode-se deduzir serem eles de baixa extração. Além do mais, um deles possui o depreciado pênis coberto de prepúcio, considerado muito vulgar pelos estetas do sexo.

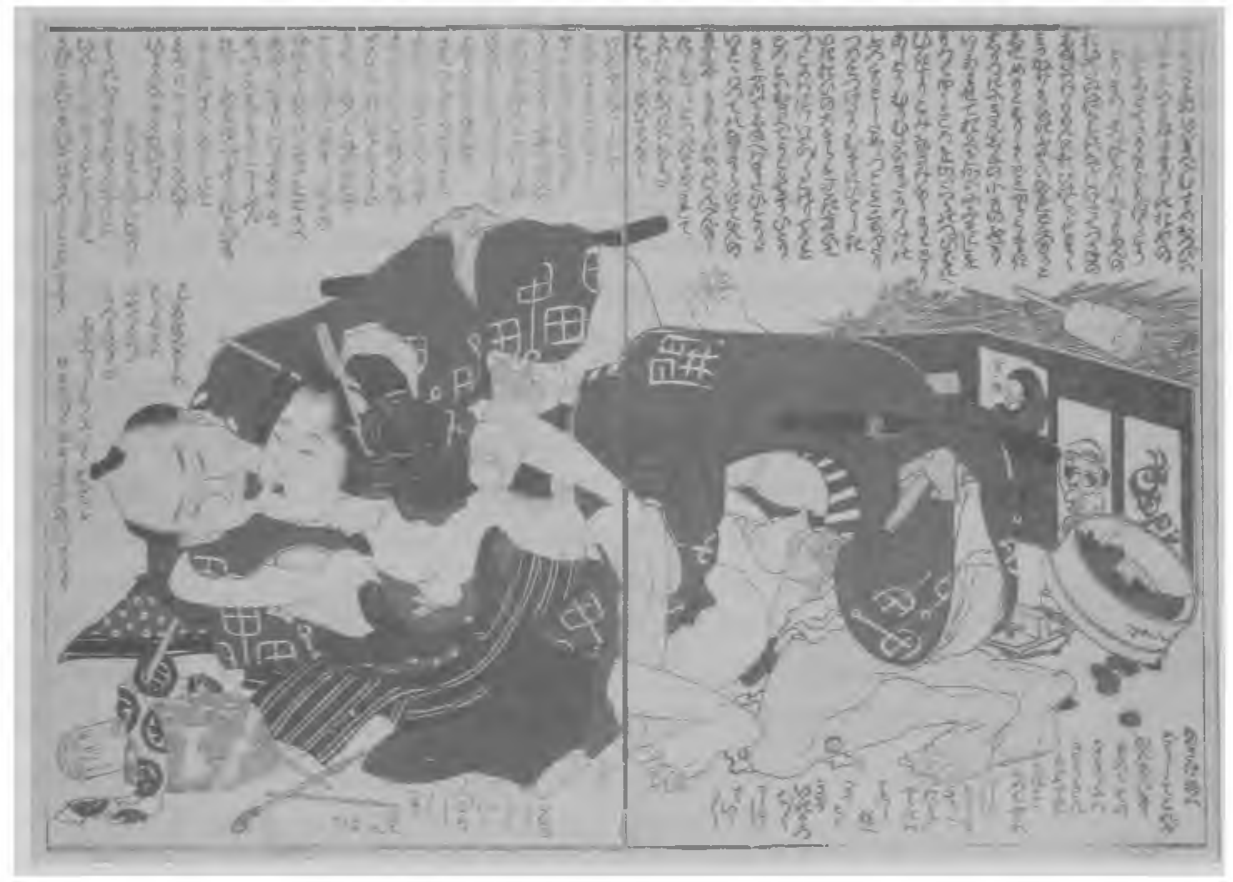




\section{Tradução}

Bem, Otsubi, a filha de Hinbei da Casa Paupérrima onde nem se comia, quando tinhas suas doze primaveras, foi enviada a servir como babá e cuidar de todos os detalhes domésticos em certa casa importante, para que seus pobres pais pudessem descansar um pouco. Sua triste figura se resumia a um quimono de dormir forrado de algodão todo remendado, tamancos de cozinha com tiras de fibras de bambu, o cabelo arrumado em penteado Shimada com a fita amarrada a mão, uma faixa de algodão muito estreita para o quimono; entretanto, por seus olhos serem brilhantes e muito bem desenhados, além de possuir um traseiro de certa forma atraente, dois jovens das redondezas se acertaram e, quando ela estava para comprar queijo de soja tôfu, tendo à mão uma cesta de bambu para pasta de soja, puxaram e enfiaram-na num canto de uma esquina e, lamentavelmente, amarram-lhe as mãos, os pés, e todo seu corpo foi imobilizado. Beliscaram sua vulvinha gordinha ainda sem pelos, encheram-na de saliva, e, quando um deles foi enfiar apressadamente no lugar seu grande pênis de vigor semelhante ao de um cavalo, saiu da montaria gritando: "are, $a a a a$ " "que dor, que dor". e ficou imóvel a se apertá-lo e quando terminou, o outro veio substituí-lo, com seu pênis comprido, sem perdoar nenhuma justificativa àquele vaso novo, enfiou e ficou rebolando lá no fundo, lá no fundo, e a pobre Otsubi era só lágrimas [hara-hara] e foi inevitável sofrer a segunda vez, com dores, com sofrimentos, ficou reduzida a andar feito caranguejo rente ao chão; com expressão de choro no rosto, acabou indo à loja de queijo, mas sua vulvinha estava púrpura e inchada, foi-lhe doloroso lavar-se numa bacia e, mesmo que esfregasse uma erva chamada sanshichi, por alguma razão desconhecida, foi ficando cada vez mais dolorida e não conseguia dormir; por isso recebeu uma folga, sem falta, e voltou para seu lar; por causa do ocorrido, a mãe, tendo aumentada a sua miséria, condoeu-se pela dor daquela vulva que era "vaso novo"', untou um brocado com um bálsamo oleoso e o aproximou de suas partes e, por algum tempo, Otsubi ficou andando de modo esquisito. Quanto a coisas intangiveis e inimagináveis, como confrontar-se com coisas inesperadas como a perda da virgindade, ou os sofrimentos, tornaram-se cada vez mais freqüentes. De acordo com as recordações de sua mãe Osase, na primeira vez que agasalhou o enorme pênis de Hinbee, pareceu-lhe uma dor insuportável.

\section{Texto inserido:}

Rapaz: Que miséria! Como é que não consegue suportar isto? Em troca, eu the comprarei um quimono tingido com o meu pagamento. Fufufuu fufufuu, Ah, ainda não entrou tanto quanto eu queria. Heee, já estou quase indo, estou quase indo, fufufuu fufufuu, aah, que bom, que bom!

3. A virgindade é referida como "vaso novo", arabachi 新鉢. 
Mulher: Está doendo! Está doendo! Está doendo! Está doendo! Aaare aare, assassino, assassino, hee! Está doendo! Está doendo!

Rapaz: Ah, vai, garota. É assim mesmo, da primeira vez dói mesmo. É só durante um tempinho. Güenta firma! Ee, que boa menina! Ee (lábios: chutsu chutsu)

Mulher: Argh, que sujo! Petsu Petsu Petsu...

Lendo-se o texto, além de elementos que conotam uma "expressão de verdade" de elementos do período (utilizando-se reflexão de Hayakawa), notam-se vários trocadilhos lingüísticos e uma inegável intenção de provocar o riso no leitor, minorando a ação violenta do assalto sexual perpetrado. Além dos signos verbais, também um conjunto de significantes visuais se insere na imagem: símbolos de boa sorte, na figura de um martelinho sobre a palha da prosperidade, uma estampa de Daruma vermelho, a divindade Hotei, uma inscrição em sânscrito apontariam, segundo Pollack (2005, p.277), ironia contrária à situação. Analisando-se a cena do ponto de vista da narrativa completa, entretanto, pode-se interpretar que estes signos justamente pressagiam a sorte que ela terá no futuro, ascendendo na escala social e econômica justamente por seu domínio na arte do sexo. Os ideogramas que marcam as vestes dos deselegantes rapazes, mitsu kinoe ou mitsu uchiwa, possível corruptela da frase miuchi wa (katto atsuku natta) [seu corpo todo (ardeu em chamas de excitação ou de vergonha ou de fúria, ou dos três sentimentos)] (Pollack, p.297) e, nas costas, kai [abertura], uma gíria de Edo para bobo [vagina], relacionam-se com a inscrição na estampa do Daruma: ichimotsu-ari ["o que tem a única e verdadeira coisa"], ou seja, termo cifrado tanto para "pênis" quanto para "dinheiro". Assim, as inscrições proporcionam uma leitura subreptícia do destino de Otsubi: através de sua "abertura" ( $t$ subi é adjetivação para uma bela vulva, redonda e carnuda) que manipula cestas de vegetais (onde se insere o termo mara [pênis]), tornar-se-á possuidora de herança e quantos ichimotsu quiser adquirir, como mostram as moedas espalhadas à sua volta. $O$ assalto que sofre é ponto marcante em sua iniciação, sem romantismo, no domínio do exercício do sexo.

Em estudo sobre a representação dos maus nas estampas eróticas, Mihashi Osamu (2005, pp.239-313), através de análises de inúmeras estampas, chega a caracterizá-los como tendo pelos, barba, rosto largo, narinas grandes, narizes largos na base, cor escura, falta de cabelos, lábios grossos, pênis com prepúcios, pés crestados, bocas grandes, pelos no ânus, sotaque provinciano, posição social inferior. Em grande parte das imagens eles aparecem ou como observadores de cenas sexuais (quase sempre em masturbação) ou como perpetradores de sexo forçado: "não se pode dizer que todas as pinturas shunga sirvam a causar prazer" (p.259), expressando, antes, "uma forte consciência da divisão de classe social" (p.295). Mihashi salienta, ainda, que, em relação à estampa aqui analisada, a última fala de Otsubi: "Argh, que sujo!" (kitanai) não deve ser interpretada como expressão de 
rejeição ao ato do assalto sexual, mas, antes, às feições nada belas dos pirralhos. Assim, conclui que no tempo de Hokusai o "desejo expresso pelos de posição inferior era visto pela sociedade como kitanai [sujo, impuro, poluído, bagunçado, feio, desagradável, indecente, grosseiro, desprezível, miserável]" Tal consideração poderia nos levar a acrescentar à expressão corrente entre nós de "feios, sujos e malvados". o adjetivo: "pobre"

Por outro lado, já sua rica vizinha na meninice, Osane (sane é um dos vários apelidos para "clitóris"), esta vai descendendo de modo diametralmente oposto, sempre marcado por um apetite sexual auto centrado, e a cena do assalto sexual que lhe é perpetrado mostra de modo acentuado sua capacidade de se satisfazer em qualquer situação, no Livro 3, imagem 4, intitulado "Décima história de Osane"

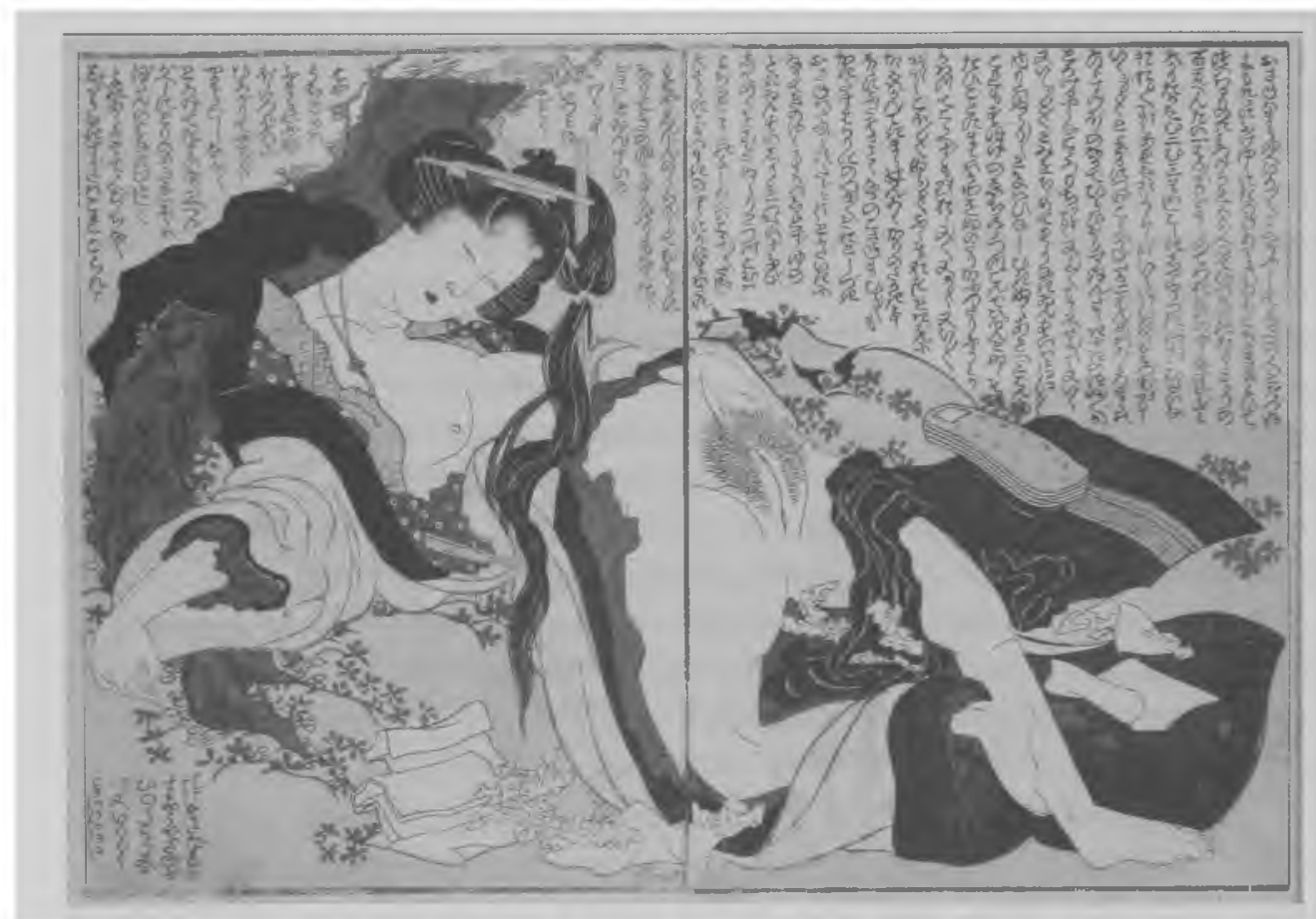

Tradução:

Osane, por causa do pênis passara por inúmeros sofrimentos. Queria visitar um conhecido, mas, como não podia visitá-lo passadas das 12 horas da noite, ficou vagando por aqui e ali quando foi descoberta por uns cinco ou seis homens de mau caráter que a agarraram e a carregaram, mil vezes já decididos. O primeiro da vez penetrou-lhe em crescendo as suas coxas, remexendo furiosamente a cabeça, um portentoso pênis-metal rijo como o ferro cujas 
grossas veias pareciam cordas de cânhamo e ela: "Ee, oo" e ele gemia: "Ei, ei, não adianta nada, ei, o, o, oo, oo, oo, fuufuu, ei, ai, oo, oo, uumumu, haa haa, vou gozar, haa, muтumu, estou perdendo haa, a consciência, yo, areare, estou indo, estou indo, estou indo, estou indo!" Enquanto agüentava o sofrimento, a segunda vez foi de Rokurôsuke, o de pênis-torno ${ }^{4}$, dentro de sua vulva que ora se expandia ora se estreitava, sentia como se seus 44 ossos estivessem para se derreter, soluçava enquanto encolhia o corpo: " $\mathrm{Ei}$, sabe?, ei, ei, de novo, de novo, aa aa aa, mais uma vez viu, mais uma vez, aa, vou gozar de novo, vou de novo, vou de novo, vou de novo, de novo!" O sêmen [emitindo sons:] byoko byoko byoko byoko byoko, escorregava suavemente na parte interna de suas coxas. Depois de este retirar-se, foi a vez do terceiro, Echigorô ${ }^{5}$, o de pênis de prepúcio; nem bem tinha enfiado e já tirava e, a cada vez, a pele de seu pênis ora era removida ora se rasgava, e mudava de gosto; Osane, não podendo agüentar mais, emitia sons gobo gobo gobo, nura nura nura, e dizia: "Oo, ei, oo, de novo de novo, de novo mesmo, de novo mesmo, de novo mesmo, vou gozar de novo, vou gozar de novo, haa haa, suu suu!" Como demorara a tirar [o pênis]!, o que seria o quarto da vez, Kanroku, o de pênis de "sete rodas", à medida em que tampava a vulva com seu instrumento "alto como um ganso", o pequeno fruto [o clitóris] de dentro dela começou a arder e, nem bem retirava ele sua brasa, já caía de lado com grande rumor. Osane, não podendo mais suportar, apenas soluçava alto: hii hii. Nem sabia quantas vezes já tinha gozado, e seus líquidos, como se fossem água quente, se transmitiam a seu rabo; achando que já fora suficiente, limpou-os, mas logo quem enfiava em meio àquela umidade era Yojirôbee, o de pênis retorcido $^{7}$ onde muitos calombos eretos envolviam suas enormes dimensões como se fossem espirais, e logo seus pensamentos se confundiram e ele, enlouquecido, não tinha limites em seu gozo: era exatamente como uma fonte a jorrar sêmen [emitindo os sons:] byoko byoko. Finalmente, para terminar os entretenimentos, Fusuke, o de pênis "casca de trigo" Estendeu-se todo sobre a vulva, yawa yawa yawa, que coxas macias. Ainda não saciados, repetiram a possessão mais três vezes; a vulva estava igualzinha a uma peônia; até a noite se abrir continuou tal desprazer. Vejam, observem esta figura tão impotente...

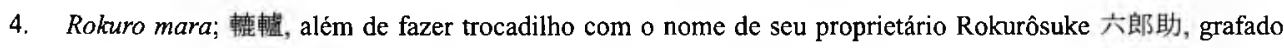
como "O sexto homem", é termo de posição sexual em que a mulher fica por cima apoiando-se nos joelhos.

5. O nome pode aludir à sua cidade de origem, Echizen 越前.

6. Assim como o trocadilho anterior utiliza imagens da técnica da cerâmica (rokuro é torno específico da cerâmica), aqui também se utiliza o mesmo procedimento: shichirin 七輪, "sete corolas de flores", é um pequeno forno redondo para brasa, feito de cerâmica ou porcelana. Kanroku (1746 1805), por sua vez, é nome de fundador de casa de calígrafos que funda o estilo kantei; ligado à companhia Nakamura de teatro kabuki, renova o estilo da caligrafia de placas de difusão das peças.

7. O trocadilho do termo "retorcido", yojire 据れ, remete ao nome Yojirôbee 与次郎兵衛, ou "soldado raso que muda de lugar várias vezes" Yojirô, por sua vez, no dialeto de Kansai, significa "cabeça de pária" 


\section{Texto inserido:}

Osane: "Ah, sabe? Aaa, parece que alguém ainda vai fazer, a semente começa a se mexer hiko hiko, ee, de novo, aa, vou gozar de novo, vou gozar, vou gozar, vou gozar."

Ainda que não se lesse a fala de Osane, a profunda expressão de satisfação (além dos inúmeros "lencinhos do amor" usados à sua volta) em sua face é reconhecível facilmente. Uma vez representados, na primeira estampa de assalto sexual, os pobres "feios, sujos e malvados", o pincel de Hokusai concentrou-os no texto, delegando à imagem a posterior expressão da felicidade, sem romanticismo.

Então, se para Otsubi o assalto sexual foi ponto de partida para o domínio da arte do sexo profissional, para Osane se tornou enlouquecedora fruição: "Vejam, observem esta figura tão impotente...", adverte-nos Hokusai, como se a criticar moralmente a entrega total à volúpia de uma "mulher amadora", que a iguala a animais, jogada na rua, na calada da noite, como mostrará estampa posterior, em atitude paralela a um par de cães.

Quanto ao sexo forçado, quando Otsubi ainda é virgem e quando Osane já está quase na queda final, em hipótese alguma se debatem sansões quanto ao ato: nenhuma revolta ou senso de injustiça sucedem o sofrimento (no caso de Otsubi) e o doloroso prazer (no caso de Osane) impingidos às mulheres. Tal situação nos leva a compreender o ato como mais uma das experiências de duas vidas que "flutuam" à deriva dos acontecimentos e, também, a não considerá-lo negativamente: não é crime, não é falta moral. Seria, antes, "falta de gosto" pois os perpetradores são feios, deselegantes e inferiores na hierarquia. Por outro lado, as (ou os, como mostram muitas estampas de jovenzinhos) que são passíveis de serem assaltadas também são inferiores em relação a outros na hierarquia, portanto "disponíveis". Tal constatação faz-nos afluir nos lábios um amargo sorriso de cumplicidade com Hokusai, que representou com tanto distanciamento situações na qual flutuam desejos somente possíveis.

O que o texto cala, a imagem profere; o que a imagem cala, o texto complementa; e, assim, o narrador pintor mostra ao leitor, incluindo-o, o sexo como a única forma que estas duas protagonistas têm de ascender, descender e fruir vidas em breves existências citadinas, provocando-nos uma compaixão característica de um "livro de sentimentos humanos", ninjôbon, em contraposição a uma compaixão aware refinada e cortesã que remontaria a Genji monogatari. 
Bibliografia

TSUJ, Nobuo 辻惟雄. “Katsushika Hokusai: Kinoeno Komatsu” 葛飾北斎 喜能会之故真 通. In: Edo Meisaku Ehon vol.5 江戸名作艶本5. Tóquio: Gakken, 1996.

FUKUDA, Kazuhiko 福田和彦 (org.). Ehon - Miwakuno ukiyoe 艶本 魅惑の浮世絵 (Livros Eróticos - Ukiyoe de Fascinação. Obras-primas de Livros-Pinturas do Período Edo, vol. 5). Tóquio: KK Besutoserâzu, 1988.

FUKUDA, Kazuhiko 福田和彦. Enshoku ukiyoe zenshû, vol.8, Hokusai 艶色浮世絵 全集 第八巻 北斎 (Coleção Livros Eróticos Ukiyoe, vol.8, Hokusai). Tóquio: Kawade, 1998, 3a . Ed. (1 ${ }^{\text {a }}$. Ed.: 1994), pp. 58-72, 186-197.

Shunga Ukiyoeno miwaku V (A Fascinação do Shunga Ukiyo-e, vol. 5). Tóquio: KK Bestsellers, 2005.

HASHIMOTO, Madalena. Pintura e Escritura do Mundo Flutuante - Ukiyo-e e Hishikawa Moronobu, Ukiyo-zôshi e Ihara Saikaku. São Paulo: Hedra, 2001.

HAYASHI, Yoshikazu 林美一 Hokusai Mangato Shunga 北斎 漫画と春画 (Pinura Erótica e Satírica de Hokusai). Tóquio: Shinchôsha, 1989.

HAYAKAWA, Monta. Shungano mikata - jûno pointo (Como Ver Shunga: Dez Pontos). Tóquio: Heibonsha, Corona Books, 2008.

MIHASHI, Osamu. "Shungano akusô hyôgen" (Expressões das Fisionomias do Mal no Shunga). In: SHIRAKURA, Y. et al., Ukiyoe shungao yomu (Lendo Ukiyo-e Shunga), vol.1, Tóquio: Chuokoron-shinsha, 2000, pp.239-313.

POLLACK, David. "Manpuku Wagôjin The Gods of Myriad Conjugal Delights: An Illustrated Erotic Story by Katsushika Hokusai" In: CARPENTER, John T., ed., Hokusai and his age. Holanda: Hotei, 2005, pp.271-297.

TANAKA, Y.; SHIRAKURA, Y.; HAYAKAWA, M.; SAEKI, J. Ukiyoe shungao yomu (Lendo Ukiyo-e Shunga). Tóquio: Chûôkôron Shinsha, 2000, 2 vols.

Dicionários especializados

KOMATSU, Keibun 小松奎文. Irono jiten 色の辞典 (Dicionário do Sexo). Tóquio: Bungeisha, 2000.

MAEDA, Osamu前田勇. Edogo daijiten 江戸語大辞典 (Grande Dicionário da Língua de Edo). $1^{\text {a }}$. Ed. Tóquio: Kôdansha, 1975.

SASAMA, Yoshihiko 䈎間良彦. Kôshoku engo jiten 好色艶語辞典 (Dicionário da Língua Erótica e Sexual). Tóquio: Yûzankaku, 1989. 